Ouvrein, G., De Backer, C. J. S., \& Vandebosch, H. (2018). Joining the clash or refusing to bash? Bystanders reactions to online celebrity bashing. Cyberpsychology: Journal of Psychosocial Research on Cyberspace, 12(4), article 5. https://doi.org/10.5817/CP2018-4-5

\title{
Joining the clash or refusing to bash? Bystanders reactions to online celebrity bashing
}

\author{
Gaëlle Ouvrein, Charlotte J.S. De Backer, \& Heidi Vandebosch
}

Department of Communication Sciences, University of Antwerp, Antwerp, Belgium

\begin{abstract}
Researchers, in studies of online news-site commenting, have found a huge number of aggressive comments and have indicated that such comments should be interpreted within the discussion context that other bystanders, such as journalists and other readers, have created. In this study, we aimed to offer insights into bystanders' reactions to negative news articles and other bystanders' aggressive comments in the specific context of celebrity news. Therefore, we subjected Flemish celebrity-news articles $(N=69)$ and the Facebook reactions $(N=5,529)$ to those articles to a content analysis. First, using a quantitative content analysis, we coded each comment as having a negative, neutral, or positive tone. Next, we conducted a qualitative content analysis, which consisted of a vertical coding phase and a horizontal coding phase, so as to investigate the comments' content in more depth and to determine which elements resulted in some comments' negative and even aggressive tone. The results indicate that most readers' reactions stayed on topic, thus merely contributing to the negative atmosphere that the journalist had already created. However, unlike the journalists, who tended to express their emotions rather subtly, the readers reacted using extreme aggressive language. Furthermore, although these aggressive reader reactions generally seemed to set an aggressive tone for future reactions, some readers broke this aggressive cycle and explicitly disapproved of the aggressive expressions.
\end{abstract}

Keywords: Celebrity bashing; bystanders; user comments; online aggression; Facebook

\section{Introduction}

Celebrities regularly become victims of online aggression in a phenomenon that has become known as celebrity bashing (Johansson, 2008). Celebrity bashing can be attributed to journalists who write mean-spirited online news reports about celebrities (i.e., media bashing) or to the audiences, who comment on the journalists' reports or attack celebrities directly via social media (i.e., audience bashing; Marwick \& Boyd, 2011). Researchers on Flemish celebrity-news coverage have indicated that audience reactions contain more aggressive elements than journalistic articles do (Van den Bulck \& Claessens, 2014). Given the vast reach of celebrity news (De Backer, Nelissen, Vyncke, Braeckman, \& McAndrew, 2007), many people are exposed to celebrity bashing and this provides them with a chance to respond to the bashing in a specific way. Such people are referred to as bystanders. In this study, we focus on how bystanders react to both media and audience celebrity bashing: What characterizes the bystanders' aggressive reactions, and how are such reactions related to the negative tone and language of the original news reports and to the reactions of the other bystanders?

Celebrity bashing is a specific type of online aggression in which a celebrity is the object of aggression and in which the bystanders are mostly ordinary people (Pyżalski, 2012). Researchers of online aggression have indicated that both personal and contextual variables determine how bystanders behave in conflicts among ordinary people (Cheng, Danescu-Niculescu-Mizil, Leskovec, \& Bernstein, 2017; DeSmet et al., 2014). Although some researchers 
have conducted research on personal traits in the context of celebrity aggression (e.g., Ouvrein, De Backer, \& Vandebosch, 2018), none have focused on contextual determinants, such as the characteristics of the discussion context (created by both journalists and other readers). A social reality that is based on other actors' attitudes and behaviors is constructed among the community of celebrity-news consumers; this results in a set of implicitly shared collective behavioral norms that strengthen the group members' social influence on each other (Ferrans, Selman, \& Feigenberg, 2012). Given the high prevalence of celebrity bashing-by journalists and readers alike (Johansson, 2008; Van den Bulck \& Claessens, 2014)-and the widespread tolerance of celebrity-focused aggression (Ouvrein, Vandebosch, \& De Backer, 2017), it is reasonable to expect that the norms of the discussion context will influence the bystanders and thereby cause them to start engaging in similar behaviors (Cheng et al., 2017; Cicchirillo, Hmielowski, \& Hutchens, 2015). However, some bystanders become aware of this social influence and try to resist it. These bystanders tend to react with humor (Lee, 2005), exhibit judgment of or disapproval toward aggressors (Erjavec \& Kovačič, 2012; Ziegele, Breiner, \& Quiring, 2014), or offer expressions of sympathy for (and defenses of) the bashing victims (Baker, 2001). This behavior can also impact other bystanders' reactions; researchers have ascertained that, when bystanders defend victims, the likelihood that other bystanders will join in on the cyberbullying decreases (DeSmet et al., 2014).

Given the limited extent of the research on the content and underlying tone of bystanders' reactions to celebrity bashing, in this study, we aim to explore bystanders' reactions to (a) negative celebrity-news articles and (b) other bystanders' aggressive comments on those celebrity-news articles. We use a quantitative content analysis to code each comment as negative, neutral, or positive. However, we focus largely on the content and underlying tone of the comments rather than on the frequency of certain words or on the number of words, generally. Therefore, we also apply a qualitative approach to further explore the content of these comments and to determine which elements produce negative or aggressive comments.

\section{Celebrity Bashing}

Celebrity news constitutes an important part of the entertainment industry (Marwick \& boyd, 2011). This is a byproduct of newspapers' late-20th-century efforts to remedy their decreasing popularity (Esser, 1999). The act of bashing celebrities has proven to be a sure way to amplify the entertainment value of their content, so journalists have increasingly participated in this practice (Johansson, 2008). Today's celebrity-news coverage is characterized by scandals and drama (Dubied \& Hanitzsch, 2014), so the written accounts of these topics routinely contain criticism of the celebrities involved (Podnieks, 2009). Johansson (2008) introduced the term celebrity bashing to refer to this mode of journalistic reporting about celebrities and defined the concept in terms of "newspapers that are picking on celebrities or displaying them making a fool of themselves" (Johansson, 2008, p. 408). We distinguish celebrity bashing from negative critiques on the basis of the underlying intentions, in accordance with the work of Dalla Pozza, Di Pietro, Morel, and Psaila (2011). A critique can be constructively motived, but bashing generally involves behaviors with harmful intent (Dalla Pozza et al., 2011). Researchers in cross-national content analyses have indicated that celebrity coverage, especially among the U.K. and U.S. media, is characterized by tactics that are remarkable for their evident determination to increase sensation (Esser, 1999). These articles also pay disproportionate attention to the (mostly female) celebrities' physical appearance and their sex and family lives (Podnieks, 2009). In regions such as Flanders, Belgium, researchers have observed mostly neutral tones in celebrity news (De Backer \& Fisher, 2012; Van den Bulck, Paulussen \& Bels, 2015); however, at times, journalists have created subtle forms of sensation produced by, for instance, citing quotes out of context (Van Gorp, 2014). In those regions, the causes for concern are largely concentrated on the kinds of celebrity bashing that the audience engages in (Ouvrein et al., 2017; Van den Bulck \& Claessens, 2014).

The emergence of audience members' online aggression toward celebrities is a more recent phenomenon boosted by the modern interactive features of communication technologies (Claessens \& Van den Bulck, 2014). In particular, news websites and their social media pages often function as breeding grounds for antisocial reader reactions (Coe, Kenski, \& Rains, 2014; Diakopoulos \& Naaman, 2011; Erjavec \& Kovačič, 2012; Gardiner et al., 2016). Moderators try to regulate the flow of negative reactions and even remove these reactions when appropriate (Binns, 2012; Cheng et al., 2017; Ziegele \& Jost, 2016). The British newspaper The Guardian, for instance, has deleted $1,400,000$ reactions for violating its community standards (Gardiner et al., 2016). Most problematic reactions in these comments are abusive toward the author or other readers, contain personal attacks (e.g., directed at the celebrity's intellect or physical appearance), or serve to mock irrelevant persons or topics (Erjavec \& Kovačič, 2012; 
Gardiner et al., 2016). These posts are typically also difficult to read and can include curse words (Cheng, DanescuNiculescu-Mizil, \& Leskovec, 2015) or sarcastic expressions (Siegel, Dubrovksy, Kiesler, \& McGuire, 1986). This behavior closely resembles trolling (Cheng et al., 2017), which generally refers to the act of making intentionally provocative, offensive, and menacing comments (Bishop, 2014) that are likely to incite disagreement and frustration among the audience (Lee, 2005). Sometimes, however, these comments degrade to include off-topic insults and name-calling as part of personal attacks intended to harm others; this is also known as flaming (Lee, 2005), and it is typically directed at specific groups of people. A critical discourse analysis of the comments left on the three most popular Slovenian news websites, for instance, revealed that, across a 6 -month period, at least one comment per day contained hate speech (Erjavec \& Kovačič, 2012). The number of comments with hate speech easily tripled for news articles about domestic politics (Erjavec \& Kovačič, 2012). Other researchers have indicated that vulnerable women, in particular, routinely become objects of gendered denigration online (Williamson, 2010).

Editors and reporters have expressed concern about this development, as it has the potential to tarnish journals' reputations and can repel certain readers (Cheng, Danescu-Niculescu-Mizil, \& Leskovec, 2014; Diakopoulos \& Naaman, 2011). With the exception of a few online news platforms that have enabled audience interaction (Reich, 2011), most such platforms continue to struggle with the increasing number of antisocial comments as they seek to maximize the manifestly enriching potential of reader comments (Gardiner et al., 2016). Being granted the opportunity to participate in the discussion, which often involves learning to negotiate a variety of opinions, can make news more relevant and significant to readers (Bowman, \& Willis, 2003) while also allowing them to develop and formulate more informed and nuanced opinions (Dylko \& McCluskey, 2012). Furthermore, readers have indicated that they place importance on the ability to read and react to online comments (Diakopoulos \& Naaman, 2011). This furnishes readers with the sense that they are being heard and can make a difference (Erjavec \& Kovačič, 2012). This is especially true in the context of celebrity-related content. Given celebrities' fame, most people have opinions about them (Reyes, 2007); this is why people like to talk about celebrities with other peopleeven those with whom they are relatively unfamiliar (Giddens, 1991). Moreover, people like to capitalize on celebrity cases to facilitate discussions on certain complex topics, such as relationship problems (De Backer et al., 2007). Such discussions are frequently characterized by comments that are quite judgmental and that are far more negative than the original news articles (Van den Bulck \& Claessens, 2014). Many bystanders are confronted with this negative discussion context, which journalists and other readers create together. The key determinant, then, is how this confrontation affects these bystanders' behaviors.

\section{Bystanders of Celebrity Bashing}

Bystanders of media bashing. News is a powerful tool for shaping public opinion on many topics and for steering behavior (McCombs, 2004). This influence can be observed in celebrity news. According to De Backer and colleagues (2007), celebrity news is powerful because readers use it as an informational guide for their own lives. De Backer and colleagues explained how people use celebrity news to acquire information about culturally appropriate or inappropriate behaviors (social norms) and about how to achieve success. Readers can learn how to become successful, for example, by considering bad examples (celebrities' failures); this explains readers' particular attraction to scandalous celebrity news (De Backer et al., 2007).

Being a regular bystander of media celebrity bashing can influence a person's perceptions of such behavior (Cicchirillo et al., 2015). Researchers have indicated that people consider media bashing to be quite acceptable, as they perceive it as journalists' jobs to be critical toward celebrities (Ouvrein et al., 2017). These lenient attitudes could decrease readers' thresholds to start experimenting with their own celebrity-bashing behavior. Moreover, readers can perceive imitation of celebrity practitioners as an effective way of becoming famous, as in the cases of several famous and high-status celebrity bloggers (e.g., journalist Perez Hilton, who runs a U.S.-centric blog that reaches a broad, international audience). Driven by the wish to become famous, these readers sometimes mimic the journalists' behavior (De Backer et al., 2007). The study's first research question (RQ1), therefore, focuses on bystanders' reactions to negative celebrity-news articles.

RQ1: How do bystanders react to negative celebrity-news articles?

Bystanders of audience bashing. Given the high prevalence of negative comments on celebrity-news coverage (Van den Bulck \& Claessens, 2014) and readers' generally high interest in celebrity news (De Backer et al., 2007), 
many readers become bystanders of audience bashing. A reader survey among bystanders from a Californiabased news site revealed that the majority of these online bystanders (65\%) regularly read other readers' reactions to news articles (Diakopoulos \& Naaman, 2011). This high number has caused journalists, editors, and scholars to ask how this negative discussion context influences bystanders' perceptions and behaviors (Cheng et al., 2017; Cicchirillo et al., 2015; Diakopoulos \& Naaman, 2011).

When reading other readers' comments, bystanders formulate ideas regarding the attitudes and behaviors of other actors, as well as the public opinion on the topic (Ferrans et al., 2012). Driven by a wish to avoid discord, people sometimes lose their own senses of morality and participate in behaviors that go against their own social norms (Vilanova, Beria, Costa, \& Koller, 2017). In this state, people's emotions and attitudes can easily be transferred and can thus form the basis for new behaviors (Cheng et al., 2017). Cicchirillo and colleagues (2015) confirmed this idea in the context of an experimental study on political flaming. Cicchirillo and colleagues (2015) found that people who were not verbally aggressive nonetheless showed an increased acceptance of political flaming after being exposed to uncivil media content. These more lenient attitudes increase the chance that these bystanders will engage in flaming behavior (Cicchirillo et al., 2015). One frequent explanation of the discrepancy between people's online and offline behavior is the online disinhibition effect. Suler (2004) described this effect as the disappearance of inhibitions in an online context. Due to the anonymity of online interactions, people feel more comfortable making negative statements that they would not make in real life (Suler, 2004). This disinhibition effect can develop in positive or negative ways. In the former case, people more easily express their emotions, fears, and acts of kindness and generosity (i.e., benign disinhibition), whereas in the latter case people use their greater freedom to use rude language, insult others, and even make threats (i.e., toxic disinhibition; Suler, 2004).

This does not imply that any person can turn into a troll, however; researchers have indicated that true trolls are only a small group of individuals who possess specific personality traits that lead them to participate in such behavior (Baker, 2001; Binns, 2012). However, ordinary people can comment in an antisocial way ('troll-like' comments) as a result of the negative contexts that trolls cause (Cheng et al., 2017). Indeed, several researchersin the naturalistic context of online reader comments (Cheng et al., 2015; Hara, Bonk, \& Angeli, 2000) and in controlled experimental settings (Cheng et al., 2017) - have pointed to a dynamic between trolls and bystanders in which the trolls seem to be able to activate needless discussions. The result is a sequence of negative bystander reactions (Thelwall, Sud, \& Vis, 2012). Moreover, as these discussions extend, the intensity of the negative comments gradually increases, resulting in a negativity spiral (Chmiel et al., 2011). These kinds of discussions mostly revolve around controversial topics, as controversy seems to motivate reader interactions (Ziegele et al., 2014). In some cases, discussions can even escalate into flame wars (Baker, 2001), which are conflicts in which an increasing number of people get involved in discussions that include numerous intensive and aggressive attacks, including biting sarcasm and scatological abuse (Baker, 2001; Siegel et al., 1986). Such flame wars usually do not end with agreement; rather, one independent party (a journalist or another bystander) tries to function as a moderator (Lee, 2005; Ziegele \& Jost, 2016). This moderation can take various forms. Whereas some moderators just ask the discussants to stop (Lee, 2005; Ziegele \& Jost, 2016), others openly disapprove of their reactions (Erjavec \& Kovačič, 2012; Ziegele, Breiner, \& Quiring, 2014), and still others react with new forms of criticism such as jokes or (sarcastic) poems (Lee, 2005; Ziegele \& Jost, 2016). Some moderators even choose a resolution strategy that involves showing sympathy and understanding for the target of the attacks-even defending that person's behavior (Baker, 2001). In the latter case, the bystander then becomes an upstander (Barlinska, Szuster, \& Winiewski, 2013). Seeing bystanders defend victims can stimulate further supportive reactions among other bystanders, thus decreasing the chances that these people will join in the negative commenting (DeSmet et al., 2014). Once a supportive and trusted climate is created, bystanders are able to more easily imitate upstanders' behaviors (Wong-Lo \& Bullock, 2014). In this case, the opposite of a negativity spiral-a sequence of positive reactions-can occur.

Researchers thus have identified some interesting interactions among bystanders on a broad variety of topics. In this study, we are interested in such reactions in the context of celebrity news. Due to celebrities' high status and the frequency with which they appear in news articles and public conversations, most people have an opinion on them (Giddens, 1991; Reyes, 2007). These conversations can go in various directions. Whereas some people strongly admire celebrities-seeing them as important exemplary figures-and use online tools to express this adoration, others use celebrities as an outlet for bashing (Claessens \& Van den Bulck, 2014). Researchers have indicated that attacking celebrities is often considered safer than attacking peers, as the chances that celebritybashing actions will backfire are basically nil (Feasey, 2008). Moreover, the online disinhibition effect can be higher 
in the context of celebrity aggression than in other context, as the perceived distance toward a celebrity-victim is higher than the distance toward a peer-victim, which makes the perpetrator feel more anonymous when bashing a celebrity (Ouvrein, De Backer, \& Vandebosch, 2018). The combination of these elements feeds the perceptions of celebrity aggression as an acceptable online behavior (Ouvrein et al., 2017); this perception can be easily transferred to bystanders of such celebrity bashing. To investigate the ways in which bystanders react to other bystanders' aggressive comments on celebrity-news articles, we formulated the second research question (RQ2):

RQ2: How do bystanders react to other bystanders' aggressive comments directed at celebrities?

\section{Method}

We conducted a quantitative and qualitative content analysis with constructed week sampling from October 22 through November 27, 2017. The data set included all the celebrity articles that were shared on the Facebook timelines of two Flemish newspapers, Het Laatste Nieuws (HLN) and De Standaard (DS), as well as the first 50 reader reactions to each (the reactions that necessarily generated the most responses on Facebook) and all the reactions to those reactions, resulting in 69 articles (43 articles from $H L N$ and 26 from DS) and 5,529 reactions (4,425 from $H L N$ and 1,104 from DS). We anonymized all Facebook reactions for the analyses. We chose to focus on Facebook posts and reactions, as researchers have indicated that the most extreme reader reactions are posted on Facebook (Ziegele \& Jost, 2016). Because our data collection took place over a relatively long period of time, we were restricted by the fact that the newspapers sometimes deleted old articles from their Facebook timelines. The large difference in the number of reactions to the $H L N$ and $D S$ articles can be explained by the fact that several of the $D S$ articles required readers to register to be able to read the whole article, thus creating a threshold that some people would not cross.

We chose $H L N$ and DS because of their large and diverse audiences. $H L N$ reaches more than 2,000,000 readers each day across its various platforms, making it market leader (CIM, 2017). The HLN Facebook has 774,000 followers. DS reaches 1,700,000 readers each day (CIM, 2017) and has 258,000 Facebook followers. Moreover, these newspapers have different reputations within the Flemish media landscape. Whereas $H L N$ is often perceived as the Flanders daily that is closest to a tabloid, DS has a reputation as a high-quality newspaper (Van den Bulck, 2011).

To interpret the articles and comments' underlying tones, we followed the quantitative coding procedure of De Backer and Fisher (2012). We coded each article and reaction as positive, neutral, or negative. A positive tone is characterized by supportive and optimistic words. A negative comment, on the other hand, is characterized by the use of hurtful words, curse words, and pessimistic expressions. A comment is neutral if it contains a neutral formulation, regardless of whether the expressed opinion is supportive of (or contradictory to) the other comments or the news article itself; a comment is also neutral if it contains a balance of positive and negative expressions. We determined intercoder reliability following the procedure of Lombard, Snyder-Duch, and Bracken (2010). The second coder completed slightly more than $10 \%$ of the data set (nine news articles and 625 reactions). This coder followed detailed instructions on how certain words, underlying feelings, and emojis were coded. For items with score differences, the two coders together decided on the final score. The average Cohen's k was 0.78 (range: .39-1.0) and the average Krippendorff's a was .83 (range: .37-1.0), indicating substantial agreement (Krippendorff, 2011; Lombart et al., 2004).

As we were mostly interested in the comments' content and underlying tone, rather than in the frequency of specific words or comments, we followed this quantitative analysis with a qualitative approach. The qualitative content analysis with open coding allowed us to further explore the types of reactions in the celebrity context, as well as to investigate specific words and expressions that contributed to the negative tone of the comments. The procedure for the qualitative content analysis consisted of two parts that answered our two research questions: a vertical coding process (RQ1) and a horizontal one (RQ2). In the first phase, we conducted a vertical or within-case analysis (Miles \& Huberman, 1994), meaning we analyzed the negativity of each news article. In this way, we looked at the negativity in each article and the ways in which the bystanders reacted to it (RQ1). Next, in the second phase, we performed a horizontal or cross-case analysis (Miles \& Huberman, 1994), which enabled us to examine the types of aggressive comments that occurred frequently in the responses to the various news articles (RQ2). In both parts, we analyzed the articles' and comments' words, metaphors, quotes, and emojis in 
order to broadly interpret the data and get an initial idea of the underlying tones of the articles and of the bystanders' reactions (Van Gorp, 2014). We included emojis in the analyses, as researchers have indicated that emojis, on social media, are used not just to express feelings but also to reveal information regarding intent (Dresner \& Herring, 2010).

\section{Results}

Based on the quantitative portion of the content analysis, we determined the number and proportion of negative, neutral, and positive articles and comments. An overview of these descriptive statistics is found in Tables 1 and 2. $H L N$ contained a higher proportion of negative news articles than did DS, but the difference was not significant. Concerning the reactions, we found that the proportion of negative reactions clearly outpaced the proportion of negative news articles; this is in line with earlier findings, which indicated that audience bashing is a bigger problem than media bashing within Flemish news coverage (Van den Bulck \& Claessens, 2014). The neutral reactions, however, formed the largest category for 31 of the 69 articles. Comparing the proportions of positive versus negative comments, 14 articles had more positive comments than negative ones, but 48 contained more negative comments than positive ones. There was also a significant relationship between the type of comments and the newspaper $\left(\chi^{2}(2, N=5,529)=67.20 ; p<.001 ; V=.11\right)$ (Table 2$)$. The proportion of both positive and negative comments was slightly higher for HLN than for DS.

Table 1. Descriptive Statistics for the Articles

\begin{tabular}{lccc}
\hline & $\boldsymbol{H L N}$ & $\boldsymbol{D S}$ & Total \\
\hline Positive & $9(20.9 \%)$ & $4(15.4 \%)$ & $13(18.8 \%)$ \\
Neutral & $26(60.4 \%)$ & $18(69.2 \%)$ & $44(63.7 \%)$ \\
Negative & $8(19.0 \%)$ & $4(15.4 \%)$ & $12(17.3 \%)$ \\
\hline Total & 43 & 26 & 69 \\
\hline Note: $\chi^{2}(2, N=69)=.56 ; n$. s.; $V=.09$ & &
\end{tabular}

Table 2. Descriptive Statistics for the Facebook Reactions

\begin{tabular}{lccc}
\hline & HLN & DS & Total \\
\hline Positive & $491(11.1 \%)$ & $77(7.0 \%)$ & $568(10.3 \%)$ \\
Neutral & $2,649(59.9 \%)$ & $808(73.2 \%)$ & $3,457(62.5 \%)$ \\
Negative & $1,285(29.0 \%)$ & $219(19.8 \%)$ & $1,504(27.2 \%)$ \\
\hline Total & 4,425 & 1,104 & 5,529 \\
\hline Note: $\chi^{2}(2, N=5,529)=67.20 ; p<.001 ; V=.11$ &
\end{tabular}

Quantitatively, the interactions between the articles' and the reader reactions' tones (Table 3) indicates that the tones of the reactions mostly matched with the tones of the accompanying articles, as the corresponding category was always the largest one. Chi-square tests indicated that the relationship between tone of the article and tone of the comments was significant $\left(\chi^{2}(4, N=5,529)=1,122.71 ; p<.001 ; V=.32\right)$. Regarding the negative news articles, several such articles received many aggressive comments. These articles contained up to $36 \%$ more negative or aggressive comments than did the articles with a positive or neutral tone.

Table 3. Crosstab Analysis of the Tones of the Articles and the Reader Reactions

\begin{tabular}{lcccc}
\hline \multirow{2}{*}{ Articles } & \multicolumn{4}{c}{ Reactions } \\
\cline { 2 - 5 } & Positive & Neutral & Negative & Total \\
\hline Positive & $117(66.8 \%)$ & $38(21.7 \%)$ & $20(11.4 \%)$ & 175 \\
Neutral & $378(8.4 \%)$ & $3,139(69.6 \%)$ & $992(22.0 \%)$ & 4,509 \\
Negative & $73(8.6 \%)$ & $280(33.1 \%)$ & $492(58.2 \%)$ & 845 \\
\hline Total & 568 & 3,457 & 1,504 & 5,529 \\
\hline
\end{tabular}

Note: $\chi^{2}(4, N=5,529)=1,122.71 ; p<.001 ; V=.32$

Bystanders' reactions to journalists' negative celebrity-news articles. The first research question concentrates on bystanders' reactions to media bashing. For this part of the analysis, we included all articles that 
had a negative tone and the positive, negative and neutral reactions they provoked ( $N=12$ articles; $N=845$ reader reactions). The qualitative analysis produced some interesting findings regarding the negative media reporting of celebrity news and bystanders' reactions to it.

Considering the content of the negative articles and comments, we found that negativity was highest when an article dealt with controversial topics such as sexism. Negative bystander reactions to those articles most often occurred when the news article dealt with a celebrity's professional or family life, as most commenters bashed celebrities on this topic. The only exception was for physical appearance. Even when a news article dealt with a completely different topic, some readers made negative comments about the celebrities' physical appearance. These comments were often quite rude, and they directly attacked the involved celebrity for being ugly.

"Their kids will be very ugly :D thin lips, big nose and teeth, typically British" (Article 37, which is about a royal engagement announcement).

Bystanders of these negative celebrity-news articles reacted with even more negativity than those of positive or neutral articles. A word-choice analysis indicates that bystanders' negative reactions were far more judgmental and hurtful than journalists' articles, which were restricted to subtle and often hidden forms of sarcasm. Bystanders' comments, on the other hand, often were aggressive and insulted the celebrity at issue. The bystanders often used exclamation marks to give their expressions more power.

Journalist: "It is quite exceptional for [a Dutch singer] to be honest,"

Bystander: "[Dutch singer], you are stupid!"

(Article 34 which is about a Dutch singer's family troubles)

Some readers appeared to be unhappy with the ways in which celebrities were treated in the negative news articles and in the aggressive bystander comments; these readers started judging the journalist. Ten bystander comments blamed the journalists for their sensational news reporting. Some bystanders also referred to the opinion that these articles were not meant to provide news but rather to stimulate aggressive reader responses and even personal threats. Readers mostly referred to $H L N$ in particular as providing bad journalism-comments that align with its reputation within the Flemish media landscape:

"This is what HLN does all the time. They say A but without B (proofs) and the result is that people start discussing and that HLN has lots of reactions on their articles and that is what it is all about on Facebook. It's all about causing conflict among people, even causing personal threats." (Article 12, which is about a Flemish actor and producer who was accused of several cases of sexual intimidation)

"This is not news. It should not be in a newspaper and it is not funny for her. . . I would be ashamed of myself if I was the journalist who put his/her name underneath this article. No one cares." (Article 25 , which is about a Dutch singer being too skinny).

Several readers even took these actions a step further and referred to the fact that people's actions have become quite absurd. These comments included criticisms of society as a whole. Some readers used sarcastic expressions to make fun of the \#metoo movement (a campaign in which many famous women have talked about their experiences of enduring sexually transgressive behavior), even in articles that had nothing to do with this topic. Other critical comments dealt with the distribution of power in society:

"In what kind of world are we living? Oh God! All of a sudden, everyone is the victim of sexual intimidation, chickens are seriously mistreated, St Nicholas' assistant is a racist, taking a plane can make you sick for the rest of your life... Jezus! You can just hang yourself if you want." (Article 15, which is about a Flemish actor and producer who was accused of several cases of sexual intimidation)

\section{Bystanders' Reactions to Other Bystanders' Aggressive Comments Toward Celebrities}

The second research question focused on how bystanders react to other bystanders' aggressive comments. For this part of the analysis, we included all articles that had negative reader reactions, disregard the positive, negative 
or neutral tone of the news article and all types of reactions to these negative reactions ( $N=67$ articles; $N=5,514$ reader reactions). First, we differentiated the types of aggressive bystander reactions. Next, we analyzed how other bystanders reacted to these varied types of comments. Only one article contained exclusively negative bystander reactions; thus, these audience discussions evolved in various ways. Moreover, there appeared to be some differences according to the target of the comment (a celebrity vs. another bystander).

Aggressive comments directed at celebrities. We regularly observed three types of aggressive comments directed at celebrities. These comments blamed the celebrity for seeking attention, for seeking money, and for being a "drama queen". We found comments regarding attention seeking in 13 articles. This type of blaming was especially common in the articles on sexual relationships, as most articles categorized under this topic dealt with the \#metoo campaign. Many readers accused women in this movement of seeking attention and even doubted the truthfulness of their stories, questioning the extent to which the women were responsible for their own negative experiences. Some of these comments were very aggressive, expressing hate for the involved celebrity.

“Why are women playing the victim? The producer wanted to have sex with her, but she didn't. Nothing happened, end of the story. But they just love to be in the center of attention" (Article 32, which is about an American actress's \#metoo story)

"Why do we even care about what [Flemish journalist and TV producer] says or does? She biases things because of her high needs for sensation and money, just like her documentary about Tenerife. This has nothing to do with sexism. It's just opportunism. I hate that woman." (Article 47, which is about a Flemish journalist and TV producer who quit the show De Slimste Mens ter Wereld because of sexual comments)

The second regular focus of blame was a supposedly excessive interest in money. Several readers were convinced that most of the celebrities' behaviors were inspired by a desire for more money. We found this argument in the comments of 18 articles regarding a wide variety of behaviors, such as the comeback of a Flemish music group, the launch of a new dress for children, and the sharing of \#metoo stories.

"A woman can defend herself, but first they want to have a career and have enough money to retire and then they start complaining that they were sexually abused and they want a compensation" (Article 26 about sexual abuse of two American film producers).

The third common source of blame was related to drama. In this context, bystanders perceived female celebrities as exaggerating their problems and therefore accused them of being soft. This category seemed to apply to criticisms of several celebrities in various contexts, and it appeared in the comments of eight articles: regarding a Flemish journalist who quit a famous Flemish show because of sexual jokes, actresses sharing their \#metoo stories, actresses involved in a case of sexual intimidation against a Flemish actor and TV producer, and a Dutch singer who was the target of many negative comments. Some comments even included gendered denigration, in which terms such as drama queen, gay, and feminism were used as curse words.

"Disgusting feminism! It makes me throw up!" (Article 65, which is about an American actress and writer and a false accusation of sexual abuse)

“This has become a witch hunt!!!!!! It's like all men and boys are animals. As a woman, I say NO! Stop the discrimination of men, femiNAZI's!" (Article 17, which is about a Flemish actor and producer who was accused of several cases of sexual intimidation).

Considering how bystanders typically react to these kinds of aggressive comments, it appears that these comments set the tone for increased aggression among bystanders. This causes the tone of the bystanders' reactions to become more negative and more hurtful; this includes blaming the celebrity even more. In 12 articles, the comments escalated. Some of these negativity spirals were characterized by increasing use of curse words and exclamation marks, whereas others contained increasing sarcasm: 
Person A: "In a world where Gangnam style can be a hit, this woman can be the most beautiful woman in the universe. ... I'm a Barbie girl in a Barbie world."

Person B: "5 kg fillers, a professional team for make-up and probably also a personal trainer. I don't call this woman a natural beauty."

Person C: "You forgot the silicon."

(Article 9, which is about the new Miss Universe)

Several readers seemed to be aware of serious forms of aggression in their comments and sometimes tried to downplay it by indicating that they had said something funny-for instance, by adding "hahaha" or emojis. We saw this strategy in comments from 14 articles.

"Too much drugs and too little talent. Haha" (Article 25, which is about a Dutch singer being too skinny).

“So, these are DJ's? ....... They only play bullshit :D :D :D :D" (Article 48, which is about a Flemish music group in the DJ Mag Top 100).

Moreover, a couple of bystanders seemed to support aggressive commenters and pointed to the fact that celebrities should be able to deal with those comments, as it is the price they pay for being famous. Some of them, for instance, referred to the fact that celebrity bashing is so common to argue that celebrities should not be bothered by it.

"[This Flemish journalist] is on television quite often. She should be quite used to this [receiving negative comments], right? That's why I have my doubts about the reasons she mentions now" (Article 4, which is about a Flemish journalist who quit the TV show De Slimste Mens ter Wereld because of sexual comments)

"It is not that bad! You know when you are famous, you have to deal with this [dealing with critics]. They should not complain about this" (Article 34, which is about a Dutch singer's family troubles).

Although several bystanders joined or supported the bashing of celebrities, others refused to participate in this practice. We also identified some bystanders who defended and even glorified the involved celebrities (i.e., taking the role of an upstander). These reactions often had a supportive character and referred to how good or beautiful the celebrity is.

"Congratulations [Flemish singer] and [her boyfriend]. I can imagine that lots of people have negative comments when you are famous. It is good that you don't get bothered about it. Good luck" (Article 36 about the first public kiss of a Flemish singer and her boyfriend)

"You should see how happy they are. This is so beautiful. You go for it. I'm looking forward to it" (Article 19 about the comeback of a Flemish band).

These kinds of reactions were often accompanied by concrete advice for the involved celebrity. Some readers even tagged or directly addressed the celebrity in their comments. Other bystanders seemed to be inspired by these glorifying comments, which were often followed by more supportive reactions, indicating that these positive reactions may have stimulated more positivity.

Dear [Flemish singer] and [his wife], what I read is very stressful for you. My nephew also had acid reflux when he was little. We went to see the pediatrician and his parents had to do a baby salve on his tummy. I will ask them for the name in case you want to try this. (Article 29 about the son of a Flemish singer suffering from backflow)

Aggressive comments directed at other bystanders. Celebrities were not the only targets of bashing; regularly, heated discussions started that had nothing to do with the topic nor the celebrity in the story. These discussions devolved into personal attacks among the bystanders, closely resembling flame wars. Several bystanders got involved in these wars, and the attacks became increasingly hurtful: 
Person A: "You are not acting like an adult, because you are insulting me in your comment, hypocrite."

Person B: "The Nazi's were wrong, because it is people like you that they should have put into the gas chamber."

Person C: "I'm wondering whether you actually have some brains."

(Article 12, which is about a Flemish actor and producer who has been accused of several cases of sexual intimidation)

Two types of aggressive personal attacks were very common. The first group of comments described other readers as being stupid or unable to read and write properly. Some readers even searched through the other users' profiles and pictures to support their arguments that those users were stupid. Readers were sometimes very creative in the curse words that they used to describe other bystanders. The conclusions in these comments often resembled the idea that "stupid" people should "just shut down".

"A moron makes less spelling mistakes than you do! And most pigs cost less to society than you do!" (Article 6)

"You should first learn how to write, you idiot. And just shut down your big mouth, you moron" (Article 16).

The second type of personal reaction involved racist or otherwise hateful speech. This hate speech was mostly concentrated around religion, even though only one of the news articles dealt with religion. Similarly, even when the topic of a news article had nothing to do with racism, readers sometimes made personal racist attacks against other (mostly Muslim) bystanders and even against asylum seekers.

"After listening to one song of this colored guy, I think this really sucks. You can't understand a word of it, just like with most of these colored asylum seekers" (Article 6, which is about the launch of a promising rapper).

As in celebrity bashing, some bystanders disapproved of these aggressive reactions and tried to stimulate more positivity in general. These positive bystanders acted in a moderator role and expressed shame for the others' negative reactions. In the comments of 30 articles, we identified such moderators. These bystanders chose various ways of moderating. Some did this in a very constructive way, such as by referring to the fact that celebrities are also human beings with feelings and that you should not judge someone without knowing that person in real life. Some of these moderators even asked aggressive commenters whether they knew the celebrity in person. Others were not able to translate their good intentions into positive reactions, but they did refer to the aggressive commenters as being stupid. These bystander comments were often actually forms of bashing.

"This 18-years old boy had already more success than any of those pathetic and soured people placing reactions here. I'm embarrassed for some people here" (Article 6, which is about the launch of a promising rapper)

“People, why do you always place so many negative comments? That's very easy, isn't it? You cannot bash someone without really knowing that person in real life" (Article 7, which about the relationship that a Dutch TV cooking star has with his children)

None of these forms of moderation appeared to be effective at reducing celebrity bashing, as the bystanders who took up the role of moderator often themselves became the objects of personal attacks.

\section{Discussion}

Researchers of online news-site commenting have pointed to the huge amount of negative online comments (Coe et al., 2014; Diakopoulos \& Naaman, 2011; Gardiner et al., 2016) and have explained how this might set the tone for other bystanders to join these clashes (Cheng et al., 2014; Cicchirillo et al., 2015). Online aggression appears to develop through a combination of personal and situational factors (Cheng et al., 2017). In this study, we focused 
on the latter, exploring how bystanders react to both negative news articles (RQ1) and other bystanders' aggressive comments (RQ2) in the specific context of celebrity news. The results of our content analysis indicated that there is some overlap between negative journalistic reporting about celebrities and bystanders' reactions to that reporting. This interaction was most common for controversial topics, such as sexism, which confirms the importance of controversy in stimulating reader interactions on news sites (Ziegele et al., 2014). Most of these comments followed the themes presented in the original news articles, with the notable exception of comments on physical appearance. Readers sometimes aggressively commented on celebrities' weight and clothes, even when the articles had nothing to do with physical appearance. This confirms that readers are even more often critical of celebrities' physical appearances than journalists are (Podnieks, 2009; Van den Bulck \& Claessens, 2014). In negative news articles on all other topics, journalists and readers generally expressed similar negative feelings, but they clearly differed in the intensity of the words that they used to describe these emotions. None of the negative news articles themselves contained personal attacks, but that strategy was very common among readers' aggressive reactions to those articles. In their own content analyses, Van den Bulck and Claessens (2014) came to a similar conclusion, thus supporting the idea that celebrity bashing is a bigger problem among readers than among the media in the Flemish press. Nevertheless, not all bystanders in negative journalistic articles responded to negative articles with aggression. Some appeared to be well aware of the journalists' sensational reporting and blamed the reporters for it. In that way, our results differ from those on adolescents' perceptions on journalists' roles in celebrity bashing, as researchers have found that adolescent girls believe that journalists are meant to be critical of celebrities (Ouvrein et al., 2017), thus placing less blame on journalists than on the readers who bash celebrities (Ouvrein, Pabian, Machimbarrena, Vandebosch, \& De Backer, 2018). Some readers even took this a step farther and reacted to negative news articles by criticizing all of society. These comments differed from the comments directed at other targets, as the negativity was often subtler and hidden within sarcastic quotes about society.

The second research question concentrated on the types of reactions bystanders have to other bystanders' aggressive comments. We found three types of celebrity bashing, with readers blaming celebrities for seeking attention, seeking money, and for being drama queens. These often aggressive comments appeared to activate more aggression among bystanders. In this way, our results match with the idea of the negativity spiral (Chmiel et al., 2011), a phenomenon that has also been observed in YouTube comments (Thelwall et al., 2012). These spirals seem to illustrate how toxic disinhibition (Suler, 2004) can steer people's aggressive online behavior, including in the context of celebrity news. Emojis appeared to be a popular way to soften the seriousness of readers' comments (Dresner \& Herring, 2010), as readers used laughing signs to indicate that their comments were meant to be funny instead of insulting; this further supports the perception that bashing celebrities is entertaining and harmless (Ouvrein et al., 2017). Some of these readers even mentioned that celebrities should be able to deal with these kinds of aggressive comments. This behavior can be perceived as a moral disengagement strategy that is meant to protect the commenter's own self-image from other people's criticism (Ouvrein, De Backer, \& Vandebosch, 2018). Given that researchers have identified an association between moral disengagement and negative bystander behavior (DeSmet et al., 2016), these expressions of acceptance could certainly lower the threshold for bystanders to start experimenting with this behavior (Cicchirillo et al., 2015). Nevertheless, not all bystanders joined in these clashes; some of them decided to react to this aggression by standing up for the celebrities. Some bystanders even tagged the celebrity at issue using the @ symbol to express their support. This feature appears to be a typical characteristic in today's interactions between celebrities and fans (Marwick \& Boyd, 2011; Stever \& Lawson, 2013).

Apart from celebrities, other bystanders were also the targets of aggressive comments-often of a very personal nature. For instance some readers mocked others' supposed lack of brains. In fact, references to other people's low intellectual levels are regularly deleted from the comment section of The Guardian (Gardiner et al., 2016). Hate speech was also frequently used to bash readers. As Erjavec and Kovačič (2012) showed, the producers of hate speech seem to misuse news items to express their hate toward certain groups. Some bystanders, though, break these negativity spirals by acting as moderators. Consistent with the existing research (Erjavec \& Kovačič, 2012; Lee, 2005; Ziegele \& Jost, 2016), this moderation can take various forms, from constructive comments to rude attempts at moderation that are actually forms of bashing. Regardless of the type of moderation, these bystanders' feedback did not affect the positivity or quality of other readers' reactions in the future, which is also in line with the previous research (Cheng et al., 2014). 
This study has some limitations. First, although previous content analyses of celebrity news (e.g., De Backer \& Fisher, 2012; Van den Bulck \& Claessens, 2014) also revealed a considerable amount of attention on sexualization in celebrity news, our results may have been influenced by the timing of our data collection. The launch of the \#metoo campaign in October 2017 resulted in lots of stories on accusations and large scandals; these covered the front pages of Flemish newspapers for several weeks, making the theme of sexual behavior very common. Moreover, the frequency and specific characteristics of an audience's reactions may differ based on the topics that are trending at that moment. Researchers could overcome this problem by collecting data over a longer period of time. Moreover, researchers could benefit from collecting data continuously instead of ex post, as we could not include comments that had been deleted over time. Second, we only concentrated on Facebook reactions. Given the various features and opportunities for communication on other social network sites (Lenhart \& Madden, 2007), different interactions might be observed on other platforms. Researchers should therefore include several platforms and compare the results. Third, Krippendorff (2011) suggested that it is not ideal for a coding system to be developed by the person who performs the coding, which was the case here due to limited resources. However, we mitigated this problem by having a second coder and showing good intercoder reliability. Researchers could also extend our quantitative analysis of bystander comments in the context of celebrity news. We gave only a first impression of the types of bystander comments regarding journalists and other bystanders. Based on our typology of these comments, scholars should be able to quantitatively determine the frequency of each type of comments in reader discussions within a larger sample of celebrity-news articles and comments.

\section{Conclusion}

Researchers have investigated the nature of online comments on news sites, and some of them distinguished these comments based on the news theme (e.g., politics; Erjavec \& Kovačič, 2012), or the gender of the target (e.g., Williamson, 2010); however, there is still little research that focuses on celebrities as the targets of negative news articles and aggressive comments. This study contributes to the existing research on online aggression through our analyses of bystander comments in the context of celebrity news. Although we identified some general patterns that matched with what researchers had observed in reader comments in general, we also identified three specific types of aggressive comments that were directed at celebrities. First, the readers blamed celebrities for seeking too much attention; some readers were convinced that almost all of their behavior could be attributed to this goal. Second, readers blamed celebrities for desiring money and even considered this to be obsessive behavior among celebrities. Third, readers depicted several celebrities as seeking out drama and making big issues of unimportant events. This commenting behavior demonstrates how readers use celebrities as an outlet for bashing (Claessens \& Van den Bulck, 2014) and indicates a need to investigate bystander comments separately in the context of celebrity news.

\section{Acknowledgements}

The authors gratefully acknowledge support of the Research Fund of the University of Antwerp (BOF DOC PRO 31932). The study design, data collection, analysis, interpretation of the data, writing of the report and the decision to submit the article for publication were the sole responsibility of the authors and were in no way influenced by the Research Fund of the University of Antwerp.

The authors would like to thank Caitlin Vandenbossche for the data collection.

\section{References}

Baker, P. (2001). Moral panic and alternative identity construction in Usenet. Journal of Computer Mediated Communication, 7(1). https://doi.org/10.1111/j.1083-6101.2001.tb00136.x

Barlinska, J., Szuster, A., \& Winiewski, M. (2013). Cyberbullying among adolescent bystanders: Role of the communication medium, form of violence, and empathy. Journal of Community \& Applied Social Psychology, 23, 37-51. https://doi.org/10.1002/casp.2137 
Binns, A. (2012). Don't feed the trolls! Managing troublemakers in magazines' online communities. Journalism Practice, 6, 547-562. https://doi.org/10.1080/17512786.2011.648988

Bishop, J. (2014). Representations of "trolls" in mass media communication: A review of media-texts and moral panics relating to "internet trolling." International Journal of Web Based Communities, 10, 7-24.

Bowman, S., \& Willis, C. (2003). We media: How audiences are shaping the future of news and information. Reston, VA: Media Center, American Press Institute.

Cheng, J., Danescu-Niculescu-Mizil, C., \& Leskovec, J. (2014). How community feedback shapes user behavior. In Proceedings of the $8^{\text {th }}$ International AAAI Conference on Web and Social Media (pp. 41-50). Oxford, UK: Association for the Advancement of Artificial Intelligence (AAAI) Press.

Cheng, J., Danescu-Niculescu-Mizil, C., \& Leskovec, J. (2015). Antisocial behavior in online discussion communities. In Proceedings form the $9^{\text {th }}$ International AAAI Conference on Web and Social Media (pp. 61-70). Oxford, UK: Association for the Advancement of Artificial Intelligence (AAAI) Press.

Cheng, J., Danescu-Niculescu-Mizil, C., Leskovec, J., \& Bernstein, M. (2017). Anyone can become a troll. American Scientist, 105, 152-155.

Chmiel, A., Sobkowicz, P., Sienkiewicz, J., Paltoglou, G., Buckley, K., Thelwall, M., \& Holyst, J. (2011). Negative emotions boost user activity at BBC forum. Physica A, 390, 2936-2944.

https://doi.org/10.1016/j.physa.2011.03.040

Cicchirillo, V., Hmielowski, J., \& Hutchens, M. (2015). The mainstreaming of verbally aggressive online political behaviors. Cyberpsychology, Behavior, and Social Networking, 18, 253-259.

https://doi.org/10.1089/cyber.2014.0355

CIM. (2017). CIM 2017: HLN bereikt marktleiderschap dat ongezien is in Europa [HLN is market leader in Europe]. Retrieved from https://www.persgroepadvertising.be/nl/blog/HLN-bereikt-marktleiderschap-dat-ongezien-is-inEuropa

Claessens, N., \& Van den Bulck, H. (2014). A severe case of disliking Bimbo Heidi, Scumbag Jesse and Bastard Tiger: Analysing celebrities' online anti-fans. In S. Reijnders, K. Zwaan, \& L. Duits (Eds.), The Ashgate research companion to fan cultures (pp. 63-74). London, England: Ashgate.

Coe, K., Kenski, K., \& Rains, S. A. (2014). Online and uncivil? Patterns and determinants of incivility in newspaper website comments. Journal of Communication, 64, 658-679. https://doi.org/10.1111/jcom.12104

Dalla Pozza, V., Di Pietro, A., Morel, S., \& Psaila, P. (2011). Justice, freedom and security. Cyberbullying among young people. Brussels, Belgium: European Union Publications Office.

De Backer, C. J. S., \& Fisher, M. L. (2012). Tabloids as windows into our interpersonal relationships: A content analysis of mass media gossip from an evolutionary perspective. Journal of Social, Evolutionary, and Cultural Psychology, 6, 404-424. http://dx.doi.org/10.1037/h0099244

De Backer, C. J., Nelissen, M., Vyncke, P., Braeckman, J., \& McAndrew, F. T. (2007). Celebrities: From teachers to friends. Human Nature, 18, 334-354. https://doi.org/10.1007/s12110-007-9023-z

DeSmet, A., Veldeman, C., Poels, K., Bastiaensens, S., Van Cleemput, K., Vandebosch, H., \& De Bourdeaudhuij, I. (2014). Determinants of self-reported bystander behavior in cyberbullying incidents amongst adolescents. Cyberpsychology, Behavior, and Social Networking, 17, 207-215. https://doi.org/10.1089/cyber.2013.0027

DeSmet, A., Bastiaensens, S., Van Cleemput, K., Poels, K., Vandebosch, H., Cardon, G., \& De Bourdeaudhuij, I. (2016). Deciding whether to look after them, to like it, or leave it: A multidimensional analysis of predictors of 
positive and negative bystander behavior in cyberbullying among adolescents. Computers in Human Behavior, 57, 398-415. http://doi.org/10.1016/j.chb.2015.12.051

Diakopoulos, N. A., \& Naaman, M. (2011). Towards quality discourse in online news comments. In Proceedings of the ACM 2011 conference on Computer supported cooperative work (pp. 133-142). New York, NY: ACM.

Dresner, E., \& Herring, S. C. (2010). Functions of the nonverbal in CMC: Emoticons and illocutionary force. Communication Theory, 20, 249-268. https://doi.org/10.1111/j.1468-2885.2010.01362.x

Dubied, A., \& Hanitzsch, T. (2014). Studying celebrity news. Journalism, 15, 137-143.

https://doi.org/10.1177/1464884913488717

Dylko, I., \& McCluskey, M. (2012). Media effects in an era of rapid technological transformation: A case of usergenerated content and political participation. Communication Theory, 22, 250-278. https://doi.org/10.1111/j.14682885.2012.01409.x

Erjavec, K., \& Kovačič, M. P. (2012). "You don't understand, this is a new war!" Analysis of hate speech in news websites' comments. Mass Communication \& Society, 15, 899-920. https://doi.org/10.1080/15205436.2011.619679

Esser, F. (1999). "Tabloidization" of news. A comparative analysis of Anglo-American and German press journalism. European Journal of Communication, 14, 291-324. https://doi.org/10.1177/0267323199014003001

Feasey, R. (2008). Reading Heat: The meanings and pleasures of star fashions and celebrity gossip. Continuum: Journal of Media \& Cultural Studies, 22, 687-699. https://doi.org/10.1080/10304310802227947

Ferrans, S. D., Selman, R. L., \& Feigenberg, L. F. (2012). Rules of the culture and personal needs: Witnesses' decision-making processes to deal with situations of bullying in middle school. Harvard Educational Review, 82, 445-470. https://doi.org/10.17763/haer.82.4.4u5v1n8q67332v03

Gardiner, B., Mansfield, M., Anderson, I., Holder, J., Louter, D., \& Ulmanu, M. (2016, April 12). The dark side of Guardian comments. The Guardian. Retrieved from https://www.theguardian.com/technology/2016/apr/12/thedark-side-of-guardian-comments

Giddens, A. (1991). Modernity and self-identity. Cambridge, England: Polity Press.

Hara, N., Bonk, C. J., \& Angeli, C. (2000). Content analysis of online discussion in an applied educational psychology course. Instructional Science, 28, 115-152. https://doi.org/10.1023/A:1003764722829

Johansson, S. (2008). Gossip, sport and pretty girls. What does "trivial" journalism mean to tabloid newspaper readers? Journalism Practice, 2, 402-413. https://doi.org/10.1080/17512780802281131

Krippendorff, K. (2011, January 25). Computing Krippendorf's alpha-reliability. Retrieved from http://repository.upenn.edu/asc_papers/43/

Lee, H. (2005). Behavioral strategies for dealing with flaming in an online forum. The Sociological Quarterly, 46, 385-403. https://doi.org/10.1111/j.1533-8525.2005.00017.x

Lenhart, A., \& Madden, M. (2007). Teens, privacy and online social networks: How teens manage their online identities and personal information in the age of MySpace. Washington, DC: Pew Internet \& American Life Project. Retrieved from https://www.pewtrusts.org/en/research-and-analysis/reports/2007/04/18/teens-privacy-and-online-socialnetworks-how-teens-manage-their-online-identities-and-personal-information-in-the-age-of-myspace

Lombard, M., Snyder-Duch, J., \& Bracken, C. C. (2010, June 1). Practical resources for assessing and reporting intercoder reliability in content analysis research. Retrieved from http://matthewlombard.com/reliability/index_print.html 
Marwick, A., \& boyd, d. (2011). To see and be seen: Celebrity practice on Twitter. Convergence, 17, 139-158. https://doi.org/10.1177/1354856510394539

McCombs, M. E. (2004). Setting the agenda: The mass media and public opinion. Malden, MA: Blackwell.

Miles, M. B., \& Huberman, M. (1994). Qualitative data analysis: An expanded sourcebook. Beverly Hills, CA: Sage.

Ouvrein, G., De Backer, C. J. S., \& Vandebosch, H. (2018). Online celebrity aggression: A combination of low empathy and high moral disengagement? The relationship between empathy and moral disengagement and adolescents' online celebrity aggression. Computers in Human Behavior, 89, 61-69.

https://doi.org/10.1016/j.chb.2018.07.029

Ouvrein, G., Pabian, S., Machimbarrena, J. M., Vandebosch, H., \& De Backer, C. J. S. (2018). Online celebrity bashing: Wrecking ball or good for you? Adolescent girls' attitudes toward the media and public bashing of Miley Cyrus and Selena Gomez. Communication Research Reports, 35, 261-271.

https://doi.org/10.1080/08824096.2018.1467833

Ouvrein, G., Vandebosch, H. \& De Backer, C. J. S. (2017). Celebrity critiquing: Hot or not? Teen girls' attitudes on and responses to the practice of negative celebrity critiquing, Celebrity Studies, 8, 461-476.

https://doi.org/10.1080/19392397.2017.1307126

Podnieks, E. (2009). Celebrity bio blogs: Hagiography, pathography, and Perez Hilton. a/b: Auto/Biography Studies, 24, 53-73. https://doi.org/10.1080/08989575.2009.10846788

Pyżalski, J. (2012). From cyberbullying to electronic aggression: Typology of the phenomenon. Emotional and Behavioural Difficulties, 17, 305-317. http://dx.doi.org/10.1080/13632752.2012.704319

Reich, Z. (2011). User comments: The transformation of participatory space. In J. B. Singer, A. Hermida, D. Domingo, A. Heinonen, S. Paulussen, T. Quandt, \& M. Vujnovic (Eds.), Participatory journalism: Guarding open gates at online newspapers (pp. 96-117). Malden, MA: Wiley-Blackwell.

Reyes, M. (2007). CHISMAX to the Max! The celebrity gossip economy. AghamTao, 16, 37-49.

Siegel, J., Dubrovsky, V., Kiesler, S., \& McGuire, T. W. (1986). Group processes in computer-mediated communication. Organizational Behavior and Human Decision Processes, 37, 157-186.

https://doi.org/10.1016/0749-5978(86)90050-6

Stever, G. S., \& Lawson, K. (2013). Twitter as a way for celebrities to communicate with fans: Implications for the study of parasocial interaction. North American Journal of Psychology, 15, 339-354.

Suler, J. (2004). The online disinhibition effect. CyberPsychology and Behavior, 7, 321-326.

https://doi.org/10.1089/1094931041291295

Thelwall, M., Sud, P., \& Vis, F. (2012). Commenting on YouTube videos: From Gueatemalan rock to El Big Bang. Journal of the American Society for Information Science and Technology, 63, 616-629.

https://doi.org/10.1002/asi.21679

Van den Bulck, H. (2011). Media: Structuur en werking [Media: Structure and Working]. Antwerpen: Acco.

Van den Bulck, H., \& Claessens, N. (2014). Of local and global fame: A comparative analysis of news items and audience reactions on celebrity news websites People, Heat, and HLN. Journalism, 15, 218-236.

https://doi.org/10.1177/1464884913488725

Van den Bulck, H., Paulussen, S., \& Bels, A. (2015). Celebrity als nieuwswaarde. Een analyse van celebritynieuws in Vlaamse kranten en ontspanningsweekbladen [Celebrity as news value. A content analysis of Flemish 
newspapers and tabloids]. Nieuwsmonitor Steunpunt Media. Retrieved from http://www.steunpuntmedia.be/wpcontent/uploads/2015/11/Nieuwsmonitor-25.pdf

Van Gorp, B. (2014). It takes two to tango: The relationship between the press and celebrities in Belgium. Celebrity Studies, 5, 423-437. https://doi.org/10.1080/19392397.2014.920209

Vilanova, F., Beria, F. M., Costa, A. B., \& Koller, S. H. (2017). Deindividuation: From Le Bon to the social identity model of deindividuation effects. Cogent Psychology, 4, 1-21. https://doi.org/10.1080/23311908.2017.1308104

Williamson, M. (2010). Female celebrities and the media: The gendered denigration of the "ordinary" celebrity. Celebrity Studies, 1, 118-120. https://doi.org/10.1080/19392390903519149

Wong-lo, M., \& Bullock, L. M. (2014). Digital metamorphosis: Examination of the bystander culture in cyberbullying SC. Aggression and Violent Behavior, 19, 418-422. https://doi.org/10.1016/j.avb.2014.06.007

Ziegele, M., Breiner, T., \& Quiring, O. (2014). What creates interactivity in online news discussions? An exploratory analysis of discussion factors in user comments on news items. Journal of Communication, 64, 1111-1138. https://doi.org/10.1111/jcom.12123

Ziegele, M., \& Jost, P. B. (2016). Not funny? The effects of factual versus sarcastic journalistic responses to uncivil user comments. Communication Research, 2016, 1-30. https://doi.org/10.1177/0093650216671854

\section{Correspondence to:}

Gaëlle Ouvrein

Department of Communication Sciences

Sint-Jacobstraat 2

Antwerp 2000

Belgium

Email: gaelle.ouvrein(at)uantwerpen.be

Editorial record: First submission received on April 28, 2018. Revisions received on August 13, 2018 and October 3, 2018. Accepted for publication on October 3, 2018.

The article is part of the Special Issue "Bystanders of Online Aggression" guest edited by Hana Machackova (Masaryk University, Brno, Czechia), Jan Pfetsch (Technische Universität, Berlin, Germany), and Georges Steffgen (University of Luxembourg, Luxembourg). 


\section{About Authors}

Gaëlle Ouvrein (MS) is a doctoral researcher at the Department of Communication Studies, research group MIOS (Media, ICT, and Interpersonal Relations In Organisations and Society) at the University of Antwerp (Belgium). Her research concentrates on the influence of negative celebrity news on adolescents' online behaviours.

Charlotte J.S. De Backer (PhD) is Assistant Professor at the Department of Communication Studies at the University of Antwerp (Belgium). She is also a member of MIOS (Media, ICT, and Interpersonal Relations In Organisations and Society), and her current research areas are situated in the domains of gossip research, celebrity studies and social food studies.

Heidi Vandebosch (PhD) is Professor at the Department of Communication Studies of the University of Antwerp (Belgium). Her research focusses on cyberbullying amongst children and adolescents (prevalence, profiles of bullies and victims, impact, and evidence-based interventions). She is also a member of MIOS (Media, ICT, and Interpersonal Relations In Organisations and Society). 